UNIVERSIDADE ESTADUAL DE FEIRA DE SANTANA

Autorizada pelo Decreto Federal $n^{\circ} 77.496$ de 27/04/76
Recredenciamento pelo Decreto $n^{\circ} 17.228$ de 25/11/2016

PPPG

PRÓ-REITORIA DE PESQUISA E PÓS-GRADUAÇ̃̃O

COORDENAÇÃO DE INICIAÇÃO CIENTÍFICA

XXIII SEMINÁRIO DE INICIACCÃO CIENTÍFICA DA UEFS

SEMANA NACIONAL DE CIENTÍFICA E TECNOLÓGICA - 2019

\title{
ANÁLISE E DESENVOLVIMENTO DE MODELOS DE LINHAS DE TRANSMISSÃO E SIMULADOR DIGITAL PARA ESTUDOS DE TRANSITÓRIOS ELETROMAGNÉTICOS
}

\author{
Emanuel Santana Santos'; João Bosco Gertrudes ${ }^{2}$ \\ 1. Bolsista AF/CNPq, Graduando em Engenharia de Computação, Universidade Estadual de Feira de Santana, e-mail: \\ emanuel.santana1514@gmail.com \\ 2. Orientador, Departamento de Tecnologia, Universidade Estadual de Feira de Santana, e-mail: \\ $\underline{\text { Jbosco.cv@gmail.com }}$
}

PALAVRAS-CHAVE: Transitórios; Modelagem; Linhas de Transmissão.

\section{INTRODUÇÃO}

A modelagem computacional é uma das formas mais comuns para estudos de viabilidade e simulação de uma situação da vida real, pois consegue representar mais fielmente o possível comportamento de um dispositivo ou nesse caso de uma linha de transmissão inteira sem necessariamente a utilização ou construção de uma linha real. Ela consiste em encontrar representações matemáticas para o funcionamento de algum dispositivo ou evento que se queira estudar, no nosso caso, uma representação de uma linha de transmissão. BRÜGGER (2008); ZANETTA (2003).

O projeto desse simulador de linha de transmissão seria acoplado junto ao projeto simulador com recurso à Modelagem Matemática e Orientada à Objetos usando a linguagem de alto nível ( $\mathrm{C}++$, Java, Python, etc..) e que tem como vantagens a facilidade de uso através da Interface gráfica amigável, alto grau de reutilização do código e facilidade de instalação e manutenção (DOS SANTOS FILHO, P.C., PAZ, GERTRUDES, J.B., 2018), já existente e que também faz parte do projeto de pesquisa "Análise e Desenvolvimento de Modelos de Linhas de Transmissão e Simulador Digital para Estudos de Transitórios Eletromagnéticos”, CONSEPE 086/2007.

\section{MATERIAL E MÉTODOS OU METODOLOGIA}

Para a realização da pesquisa, foi necessário utilizar de ferramentas como o MATLAB. O MATLAB é um software composto por diversos módulos para diversas áreas de pesquisa, cada um com suas especificidades e ferramentas, desde o seu módulo básico 
de cálculos (core do software), até módulos específicos para data analytics, robótica, processamento de sinais.

Além do MATLAB foi necessário buscar fórmulas que descrevessem as linhas de transmissão trifásicas, sua representação e também as fórmulas para resolução dos cálculos das mesmas. Abaixo está o modelo PI que pode ser utilizado para representar a linha de transmissão implementada para análise no projeto.

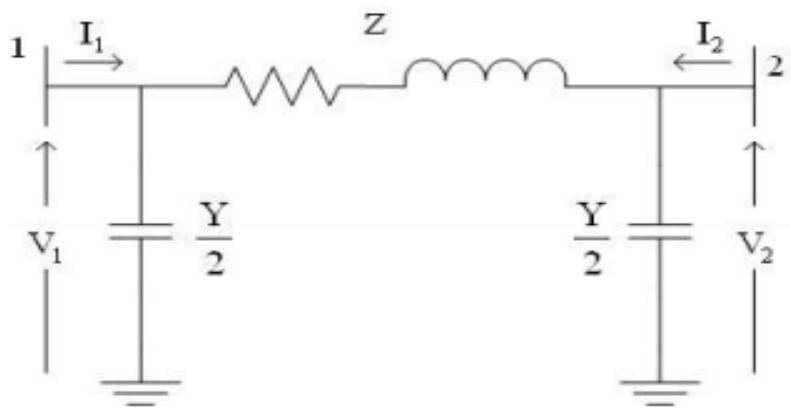

Figura 1: Modelo PI de representação de uma linha de transmissão. Fonte (LEMOS, 2008).

\section{RESULTADOS E/OU DISCUSSÃO}

O modelo computacional foi implementado apenas no MATLAB através das equações do modelo matemático de linhas de transmissão trifásicas e dos parâmetros fornecidos pelo fabricante dos condutores utilizados na base de cálculo. No caso dos cabos para existirem resultados bem próximos dos reais foram utilizados os parâmetros dos cabos com alma de aço produzidos pela NEXANS, onde todos os valores de especificação dos cabos são mostrados no datasheet do material. Isso não restringe que outros condutores possam ser utilizados, só é necessário que se alterem os seus parâmetros para encontrar novos valores com a simulação.

Vale salientar que foi utilizado apenas um cabo por fase, com distância simétrica entre eles e também em relação ao solo e levado em consideração uma linha trifásica, a figura 2 mostra o modelo de torre utilizado nos cálculos.

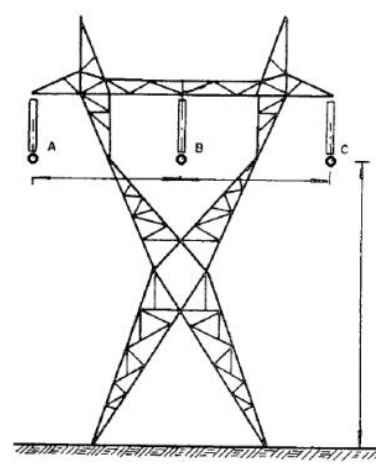

Figura 2: Modelo de torre utilizada no cálculo da linha. Fonte (ANDRADE, 2016) 
Com especificação dos cabos (condutores), resistência, frequência, distância entre as fazes, distância da flecha foi possível chegar aos resultados das imagens abaixo, que mostram como se comporta a impedância e indutância ao longo da distância. Onde nós vemos que a impedância tende a crescer com o aumento da distância em relação ao ponto inicial da linha, assim como há também um crescimento na impedância a partir do aumento da frequência na linha de transmissão.
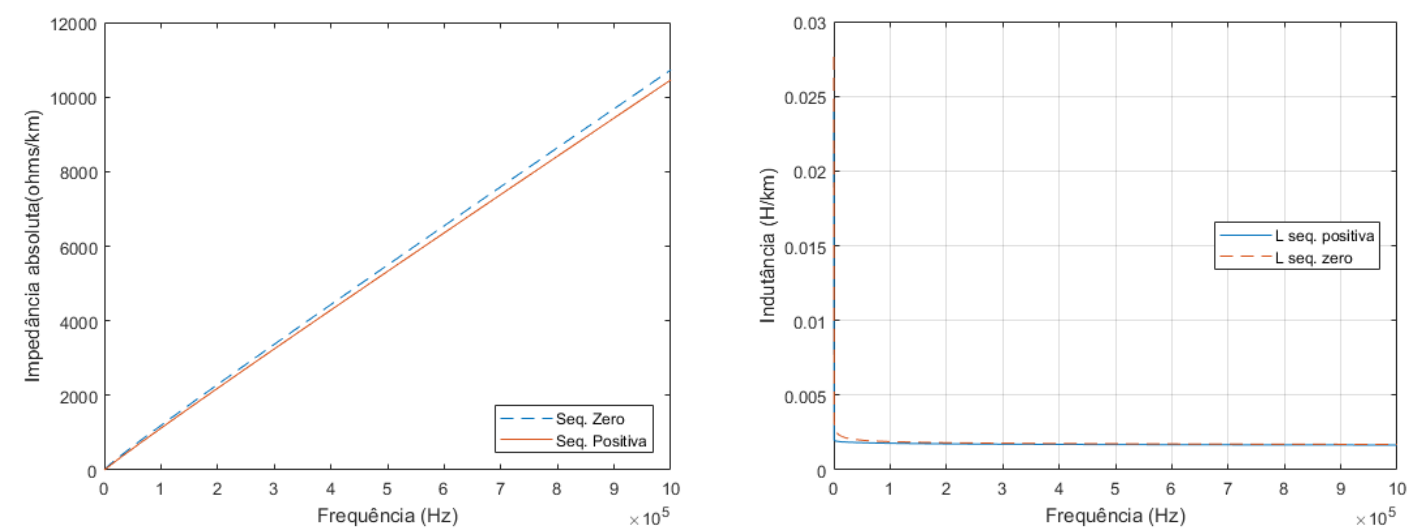

Figuras 3 e 4: Gráficos que representam respectivamente em ordem a impedância absoluta da linha e a indutância da linha com variação da frequência até $1 \mathrm{Mhz}$. Fonte (Próprio autor).

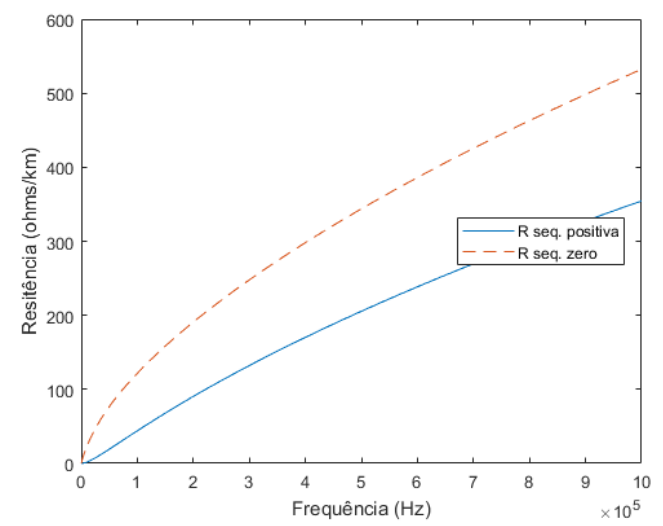

Figura 5: Gráfico que mostra o comportamento da resistência por unidade de comprimento na linha de transmissão, com variação da frequência até $1 \mathrm{Mhz}$. Fonte (Próprio autor).

O projeto não leva em conta testes com a variação do solo, como é o caso de GERTRUDES (2010), que prova que o solo deve ser levado em consideração não como um valor constante, e sim com um valor variável, assim nesse projeto o solo foi considerado com um valor constante. Assim foram gerados os gráficos citados acima e também matrizes de impedância e capacitância.

\section{CONSIDERAÇÕES FINAIS}

Como pode ser visto na comparação acima é possível observar que os resultados obtidos com os scripts implementados no MATLAB tiveram como resposta, resultados aproximados dos resultados reais encontrados em softwares comerciais que são utilizados para simulações nessa área, com isso temos que o projeto foi bem-sucedido 
em modelar e representar bem esses cálculos. Mas como o projeto foi implementado utilizando apenas o MATLAB, fica como proposta que ele possa ser implementado em linguagem de programação de alto nível $\mathrm{C}++$, para que possa sem acoplado ao simulador UEFS que está em desenvolvimento. Além disso ainda está longe de ser o projeto que possa representar matematicamente a variação de resistência no solo que é um dos grandes pilares do projeto geral.

\section{REFERÊNCIAS}

BRÜGGER, RAPHAEL MENDONÇA. "Modelagens de linhas de transmissão utilizando aplicações computacionais do visual basic." (2008). Disponível em: $<$ https://pt.scribd.com/document/290587998/Modelagens-Linhas-Transmissao-VisualBasic> Acesso em: 7 fev. 2019

ZANETTA JÚNIOR, L. C. "Transitórios eletromagnéticos em sistemas de potência", 1. ED. [S.L.]: EDUSP, 2003.

DOS SANTOS FILHO, P.C. "Desenvolvimento de Interface Gráfica E Software de Simulação de Circuitos Elétricos Utilizando o Método de Integração Trapezoidal", Trabalho de Conclusão de Curso de Graduação,127 Páginas, Fev. 2018.

DOS SANTOS FILHO, P.C.; PAZ, M. A., GERTRUDES; "Desenvolvimento de Um Simulador EMTP para Circuitos Elétricos com Modelagem Orientada a Objetos", Artigo Científico (em Preparação para Submissão ao XXII CBA 2018), 08 Páginas, última versão Corrida em 01/04/2018.

GERTRUDES J. B., TAVARES M.C., PORTELA C.; "Influência da Variação da Condutividade e Permissividade do Solo com a Frequência no Cálculo da Impedância Longitudinal e da Admitância Transversal De Linha de Transmissão: Análise de Sensibilidade para Caso de Condutor Único", Revista SBA, submetido em 03 de dezembro de 2009, aceito para publicação em18/02/2010.

ANDRADE, BRUNO SIQUEIRA “Implementação Dos Cálculos De Parâmetros Elétricos De Linhas De Transmissão Aéreas", trabalho de conclusão de curso de graduação 135 páginas, $2016 \quad<$ http://www2.dee.cefetmg.br/wpcontent/uploads/sites/18/2017/11/TCC_2016_1_BSAndrade.pdf> acesso em: 08 de agosto 2019.

LEMOS, J. R. F. "Modelagem de linhas de transmissão para estudos de transitórios eletromecânicos." (2008). 